\title{
The Future of General Internal Medicine
}

\section{Report and Recommendations from the Society of General Internal Medicine (SGIM) Task Force on the Domain of General Internal Medicine}

\author{
Eric B. Larson, MD, MPH, Stephan D. Fihn, MD, MPH, Lynne M. Kirk, MD, Wendy Levinson, MD, \\ Ronald V. Loge, MD, Eileen Reynolds, MD, Lewis Sandy, MD, MBA, Steven Schroeder, MD, \\ Neil Wenger, MD, MPH, Mark Williams, MD
}

The Society of General Internal Medicine asked a task force to redefine the domain of general internal medicine. The task force believes that the chaos and dysfunction that characterize today's medical care, and the challenges facing general internal medicine, should spur innovation. These are our recommendations: while remaining true to its core values and competencies, general internal medicine should stay both broad and deep-ranging from uncomplicated primary care to continuous care of patients with multiple, complex, chronic diseases. Postgraduate and continuing education should develop mastery. Wherever they practice, general internists should be able to lead teams and be responsible for the care their teams give, embrace changes in information systems, and aim to provide most of the care their patients require. Current financing of physician services, especially fee-for-service, must be changed to recognize the value of services performed outside the traditional face-to-face visit and give practitioners incentives to improve quality and efficiency, and provide comprehensive, ongoing care. General internal medicine residency training should be reformed to provide both broad and deep medical knowledge, as well as mastery of informatics, management, and team leadership. General internal medicine residents should have options to tailor their final 1 to 2 years

Received from the Group Health Center for Health Studies (EBL), Seattle, Wash; University of Washington Harborview Medical Center (SDF), Seattle, Wash; University of Texas Southwestern (LMK), Dallas, Tex; University of Toronto (WL), Toronto, Ontario, Canada; The Southwestern Montana Clinic (RVL), Dillon, Mont; Beth Israel Deaconess Medical Center (ER), Boston, Mass; United Health Care (LS), Minneapolis, Minn; University of California (SS), San Francisco, Calif; UCLA Medical Center (NW), Los Angeles, Calif; and Emory University (MW), Atlanta, Ga.

The longer version of this report is available at http:// www.sgim.org/futureofGIM.pdf.

Members of SGIM Task Force on the Domain of General Internal Medicine: Eric B. Larson, MD, MPH-Chair; Ronald V. Loge, MD; Eileen Reynolds, MD; Wendy Levinson, MD; Lynne M. Kirk, MD; Mark Williams, MD; Neil Wenger, MD, MPH; Steven Schroeder, MD; Stephan D. Fihn, MD, MPH-Special Consultant; Lewis Sandy, MD, MBA-Special Consultant; Martin Shapiro, MD, PhD-SGIM President (2002-03); Judy Ann Bigby, MD-SGIM President (2003-04).

Address correspondence and requests for reprints to Dr. Larson: Director of Group Health Cooperative's Center for Health Studies, 1730 Minor Ave, Suite 1600, Seattle WA 98101-1448 (e-mail: larson.e@ghc.org). to fit their practice goals, often earning a certificate of added qualification (CAQ) in special generalist fields. Research will expand to include practice and operations management, developing more effective shared decision making and transparent medical records, and promoting the close personal connection that both doctors and patients want. We believe these changes constitute a paradigm shift that can benefit patients and the public and reenergize general internal medicine.

KEY WORDS: primary care; medical education; physician payment; hospitalist; geriatrics.

J GEN INTERN MED 2004; 19:69-77.

$T$ he Society of General Internal Medicine (SGIM) is dedicated to improving patient care, education, and research in primary care and general internal medicine. The primary care movement of the 1970s reestablished general internal medicine, which grew until the early 1990 s; $^{1}$ but now many question our field's future.

Practitioners remain committed to providing highquality primary medical and hospital care and ongoing personal relationships with patients across a broad age group, especially the growing number of seniors, chronically ill adults, and people with multiple diseases. However, many practitioners struggle with low reimbursement, increasing administrative burdens, and demands for brief (5-minute) visits that frustrate doctors and patients. ${ }^{2}$ Declining application rates to U.S. medical schools show medicine is less attractive. ${ }^{3}$ Anecdotes suggest that debt-laden students entering medical school interested in generalist disciplines, including general internal medicine and especially family medicine, are discouraged by the fields' uncertain financial status ${ }^{4}$ - turning instead to ancillary specialties such as anesthesiology, pathology, radiology, and higher paying subspecialties like orthopedics, ophthalmology, cardiology, and gastroenterology. ${ }^{5}$

Like practicing general internists in the community reporting increasing role strain, ${ }^{6-8}$ many academic general internists now face rising demands for productivity, brief visits, and administrative burdens. ${ }^{9,10}$ Academic general internists have increasingly been pressed into clinical service as academic clinical enterprises have expanded.

For patients, the health care environment is rapidly changing, and access to primary care is declining especially 
for the poor and disadvantaged minorities. ${ }^{11}$ Medical science keeps making major strides in the effectiveness of preventive, acute, and chronic care. However, the delivery system is plagued by marked inefficiencies, a quality chasm between the best possible care and routine everyday care, ${ }^{12}$ previously undisclosed problems related to medical errors and unsafe systems, ${ }^{13}$ and more than 40 million uninsured Americans lacking access to general medical care. Threats of terrorism and global infectious diseases have exposed Americans to the health care system's insufficient preparation for dramatic catastrophic events. ${ }^{14}$ People with enough wealth seek "boutique" practitioners offering the care that most insured people once expected as routine. Meanwhile, fewer generalists and specialists accept new Medicare patients because of declining reimbursement rates. ${ }^{15}$

\section{THE CHAOS THAT CHARACTERIZES U.S. MEDICINE FOR MANY PATIENTS AND DOCTORS TODAY SHOULD SPUR INNOVATION}

Rather than fear change and be paralyzed into living with the chaos we know, we should see chaos as an opportunity to promote new solutions. We will serve patients better by actively defining and pursuing a paradigm shift in our field than by simply waiting to see what happens. It is in this context that the SGIM established a task force to examine the domain of general internal medicine, now and in an uncertain future.

The task force started by reflecting on Francis Peabody's famous centering message- "The secret of the care of the patient is in caring for the patient," ${ }^{16}$ - and the first phrase of the SGIM's mission statement, "to promote improved patient care." We then defined a paradigm shift, which should drive where general internal medicine develops, guided by what is best for patients and the public at large. This shift has implications for clinical practice, teaching, and research that lead to our recommendations.

\section{CORE VALUES}

As medicine advances and becomes more chaotic, general internal medicine must adapt, while remaining true to its strengths-its core values and competencies. These time-honored core values, which patients appreciate, ${ }^{17}$ have distinguished and sustained general internal medicine (see Table 1).

Our field's hallmark is expertise in caring for adult patients, especially those with complex and chronic illnesses. Most general internists provide high-value, comprehensive, and longitudinal patient care for both the healthy and infirm and coordinate complex treatment within a health care system. That longitudinal care can last decades, through health and illness, as medical issues come, go, and grow in number and complexity. It can be delivered primarily to outpatients, with inpatient care provided by hospitalists, who as general internists provide the high-value, complex care our field values; or the same general internist can act as both an outpatient and hospitalist physician. Now, especially in mature practices, older patients receive much of that care. ${ }^{10}$

Some may dismiss lifelong care to individuals as anachronistic; but patients seek and value such care in their doctor-patient relationship. ${ }^{18,19}$ Patient care depends on effective communication, with patients and other health professionals alike. General internists value a close, at times intimate, personal connection ${ }^{18-20}$ and are "adult-tricians" as in the American College of Physicians (ACP)'s slogan, "Doctors for Adults."

Although not unique to general internal medicine, strong emphases on quality outcomes and both primary and secondary preventive services mark the field. General internists have cultivated a commitment to evidence-based practice-with scientific and intellectual rigor, adhering to evidence-based medicine, and expecting to use and share this knowledge. Like all professionals, general internists place a high value on education, including lifelong learning. Many also promote education for their colleagues, other health professionals, and trainees. General internists also place high value on educating their patients, as well as the lay public in general. We are often the information managers for our colleagues and patients. ${ }^{21}$

Adaptability has been a hallmark of the specialty of general internal medicine. This is demonstrated by a willingness to take on the newer realms of clinical medicine (e.g., refugee care and HIV care), therapeutics, communications, and diagnostic and information technologies.

Leadership is emerging as a core value in general internal medicine. Internists appreciate that understanding context is key to good outcomes - especially for patients, but also for the institutions and societies where internists work.

Professionalism, a widely held value in medicine, is particularly respected in general internal medicine and draws many to the field. ${ }^{22}$ Empathy and compassion, which ground patient-centered medical care, have sustained many internists during these troubled times.

\section{ADAPTING TO A CHANGING ENVIRONMENT}

The chaos of American medicine challenges many of the traditional assumptions that general internal medicine has cherished. Some are probably not worth defending, while others are intrinsic to our specialty and will thrive through the coming paradigm shift.

Ideally, the practice of general internal medicine empowers patients to achieve better health outcomes, ${ }^{23}$ while contributing to the public's well-being. Our advocacy for our field must always be grounded in our ultimate goals of improving the medical care we provide and the health of patients and the public-not any short-term gain for individual doctors or medical institutions. It is challenging to balance professional well-being with the interests of patients and the public; but we dare not abandon these aspirations. Generalists are needed to understand the complex context in which we care for individual patients and confront both our general and local health care 
environments. As Schroeder has written, if generalist care is abandoned, it will need to be reinvented-again! ${ }^{9}$ The field should not stand still but needs to embrace new models that coordinate and synthesize care. ${ }^{24-26}$

\section{Breadth and Depth}

Breadth and depth are typically required of many general internists. Our distinguishing identity is care of older adults and patients with multiple, complex, chronic diseases. ${ }^{10}$ As the principal practitioner for adults, general internists must acquire skills "owned" by other specialtiesgynecology, dermatology, orthopedics, otolaryngology, psychiatry, and internal medicine subspecialties.

Breadth and depth are especially valuable for an aging public seeking maintenance of functional well-being from practitioners who understand both simple and complex management of common chronic diseases. General internists have training in pathophysiology and therapeutics and fascination with diseases of adults and the changes that occur in the adult life cycle. Yet open questions remain: does the marketplace value that understanding ${ }^{27}$ and is there objective evidence that it translates into better chronic disease management and outcomes, including more satisfied patients, ${ }^{23}$ and can general internal medicine have multiple overlapping foci encompassing chronic disease care, primary care, hospital care, and a commitment to generalism? ${ }^{28}$

While breadth and depth constitute our field's distinguishing features, they are perhaps its greatest challenge for individual practitioners. Both breadth and depth are relative and vary by where general internists practice and patients receive care. General internists feel wearied by rising expectations to work harder and do more care, adding new skills while maintaining existing ones. Instead, today's systems of care need redesigning.

\section{Old Assumptions}

Several traditional assumptions that general internal medicine has cherished are either invalid or irrelevant to a new paradigm: first, we should acknowledge that we do not enjoy absolute professional autonomy; in fact, we live in an increasingly competitive, mercantile environment. ${ }^{27-29}$

The practice of general internal medicine is not always primary care. Some general internists do primary care some of the time. Most family practice physicians do primary care most of the time. General internists do-and should do-both "uncomplicated" and complex primary care. Patients see both as essential, with uncomplicated care often the first step in developing an ongoing doctor-patient relationship.

We should abandon our preoccupation of competing with family medicine. There clearly are differences in cherished values of general internal medicine and family practice; but we must focus on what our patients value, not on "tribal" professional distinctions. ${ }^{18}$
Today the notion of a well-rounded generalist physician who can care independently for all types of patients, referring only a small fraction of cases to specialists, seems obsolete. Generalist physicians, working independently, cannot deliver flawless care to all patients across a broad spectrum of disease, when provided very limited time and support. Instead, we must devise creative ways to manage patients jointly with subspecialists. ${ }^{30-33}$ Generalists working in concert with specialists appear to provide the best quality of care. ${ }^{34}$ Patients are less interested in who provides care than in its technical and humanistic quality. Ultimately, in collaboration with specialists, and ever mindful of public preferences, general internists must choose which areas they will commit to master; where they will maintain breadth, not depth; and where breadth and depth vary by a practice's context. Individual internists will abandon certain areas.

\section{Communication}

General internists occupy a unique niche in interpreting information and promoting self-management, with an intellectual rigor that many patients value. Advances in information systems, especially asynchronous, secure, clinical e-mail and other real-time systems for efficient information and data exchange, make collaboration and communication easier than ever. ${ }^{12}$

Health care demand and costs are increasing. As "baby boomers" enter old age, they will have a huge impact on health care. Communication technology will increasingly affect practice and education and create more empowered patients. Already competition and consumerism have led to so-called tiered medical care, including "boutique medicine". 35

The growing diversity of cultural and ethnic groups in our country challenges doctors' communication skills and cultural competence, especially for clinicians offering history taking, doctor-patient relationships, and cognitive skills as key services.

\section{Mastery}

Professional satisfaction will be increasingly rooted in attaining mastery. ${ }^{36}$ Market and social forces challenge our aspirations to apply mastery to patient care-especially since our areas of mastery are typically cognitive, not procedural. Even the best generalist cannot have breadth and depth in all areas of medicine. Rather, mastery in one area should be superimposed on breadth and context in others-to benefit our patients.

Training in practice management and team leadership are critical yet lacking, so these skills develop haphazardly. Internal medicine residents experience training and delivery models that differ widely from the actual practice of most general internists. ${ }^{37}$

Expectations about what general internal medicine should do vary from one extreme of adding an endless array 
of tasks to restricting the field's domain. New procedures and skills are typically incorporated more quickly in specialty practice, and reflect financial incentives of a marketplace that favors new procedures. ${ }^{38}$

Medicine's workforce is changing dramatically. ${ }^{39}$ The current practice environment of general internal medicine does not match the lifestyle expectations (time with family, finances, personal autonomy) of students and physiciansin-training. ${ }^{40,41}$

\section{A VIEW TO THE FUTURE: OF WHAT KIND OF CARE IS INTERNAL MEDICINE UNIQUELY CAPABLE?}

Information, including real-time streaming data, is increasingly moving from patient to doctor in some common databases. Such systems enhance two-way communication and connectivity but likely decrease physical visits. As such systems move into community-oriented, primary care settings, general internists (and family physicians) may be the practitioners most attuned to what patients want: information and care management, as participants in the patient's and family's health care team.

Ideally, all Americans would have access not only to care but also to better information about what services accomplish and cost. By supporting excellence in medical practice, an ideal system would lead to good outcomes through shared information and well-designed structures. Physicians would be paid for everything they do, including nonoffice services (for example, phone and e-mail consultation). ${ }^{38}$ Payment would also be based on complexity and conceivably also on meaningful measures of quality of care. Point-of-service clinical information systems and decision aids based on published literature would be available to patients and families. A scenario with a view to the future can be viewed at http://www.sgim.org/futureofGIM.pdf.

At its core, the domain of general internal medicine will remain primary and principal care of adults-either directly or as a member of a team. General internists will keep seeking and filling voids as they become evident, to meet patients' rising expectations and demand for technical quality of care. Internal medicine will be dominated by common chronic diseases ${ }^{42,43}$ including heart disease, diabetes, arthritis, pulmonary diseases, neurodegenerative disorders, and general therapeutics, especially drug therapy. Competency in geriatrics will become increasingly important. $^{44}$

Chronic and complex disease management and primary medical care-especially for preventive, patientactivating, behavior change, and adherence- and healthpromoting services-will be increasingly evidence based. General internal medicine will move to a system of management designed to monitor and promote successful outcomes. Practitioners must be both comprehensive and efficient, monitoring outcomes of patients in their practice regularly and routinely.

Doctors will work in systems and thus must have mastery in systems thinking and development. Clinical skills will be valued and closely linked to communication skills. The internist's unique role will involve interpreting and applying the knowledge stream and managing information and knowledge as part of an ongoing personal and caring relationship with patients, as well as educating colleagues and team members.

Team members will change over time, but the internist, patient, and family will remain constant. Team members (e.g., cardiologists, other generalist physicians, nurses, case managers, physician extenders, and others) will review data online, usually asynchronously. General internal medicine specialists will be able to provide the majority of care that a particular patient with a chronic disease requires. To accomplish this, they must be trained to achieve and maintain expertise in problems commonly found in adult medicine (including those in the domain of other subspecialties) and able to coordinate care across a health care system.

At the same time, general internists will communicate closely with specialists who comanage patients with complex diseases. Instead of providing parallel, often uncoordinated services, all those involved in caring for a patient will seamlessly coordinate for optimal quality and efficiency. ${ }^{24,30,31}$ As experts in chronic illness management, general internists are well-suited to communicate effectively with specialists and to integrate their recommendations into an individual plan of care.

As demands rise for quality performance measures, general internists should become the quality-accountable physicians. This role will be challenging, given recent evidence that spending more on care does not boost access or quality, ${ }^{45,46}$ and subsequent pressures to reduce spending. ${ }^{47,48}$

\section{IMPLICATIONS FOR PRACTICE, TRAINING, AND RESEARCH}

Supporting optimal patient care guides our vision for the future of general internal medicine. That vision includes team-based medicine practices designed to serve patients better, support our field's core values, and provide more cost-effective service-over the long term and not just driven by short-term profitability concerns. Practice organization should promote professional satisfaction, so doctors are happier and student interest remains high.

\section{Practice}

In the future, we believe most general internists (including those working in training programs) will belong to teams; many will lead teams ${ }^{49}$ rather than practicing autonomously. The team, comprising nurses, pharmacists, social workers, other professionals, and other physician specialists, will be organized based on characteristics of people or populations served. It will be designed to provide primary and principal care, including care of people with common chronic diseases. Use of the chronic care model will become increasingly prevalent as a design principle. ${ }^{24,30,31}$ System supports are required for the team 
to function well-both information infrastructure and human resources.

A more open, proactive system will emphasize patient involvement in self-care and self-efficacy. Patients will be more involved and more responsible for their own health care-which will require additional flexibility. ${ }^{25}$ In some cases, the team may be broadened to include nontraditional health care providers, who can provide evidencebased practices tailored to meet outcomes that patients value.

Current traditional fee-for-service financing does not accommodate this model and will be a barrier to achieving the best possible patient care. ${ }^{50}$ Much work is needed to develop and adopt new reimbursement systems designed to promote this new model. We hope this report is the first step in the path to a new model. Patients need a system that will give physicians incentives, rather than penalizing them, for providing cognitive services: a time-based metric (similar to the legal profession), a salary system, patient management fees, or capitation. ${ }^{51}$ These approaches to payment will encourage health professionals to work closely together, as opposed to the present fee-for-service system, which discourages collaboration. Barriers that keep physicians from spending adequate time with patients need to be removed, including current administrative burdens and unreasonably rigid "brief-visit-only" scheduling. Electronic records and secure clinical e-mail may help reduce administrative burden and should further promote reimbursement changes. ${ }^{25}$

Physicians will need to participate in, and welcome openly, measurement designed to promote quality improvement and more open information exchange. Patients will likely feel much more confident as they experience increased information sharing and better guidance from physicians and the health care team.

At the national level, priorities need to change to provide funds designated solely to develop a better infrastructure for medicine and patient care across a continuum involving many settings of care, across specialties, and including procedures obtained in diverse settings. To date, there are no effective systems designed to promote physician self-care. Voluntary societies, large physician groups, or nonprofit service groups would do well to fill this gap.

\section{Training}

We believe that residency training programs should train pluripotent generalists, capable of practicing in any setting that they choose, and with a field of generalist expertise related to a likely practice site. The internist practicing today and in the future needs a wide array of skills, many of which are not mastered in current training programs, which focus on inpatient care in a traditional model. Small primary care programs do address a wider range of necessary knowledge and skills. However, few if any large training programs have heeded the call, now almost 2 decades old, for training that is more relevant, more ambulatory, more procedure based, and more applicable to practice in the broad range of settings and populations in which general internists work. ${ }^{37}$

Inpatient training must be geared to modern practice. ${ }^{52}$ Patients on the general medical service in our hospitals are sicker, take more medications, stay fewer days, and require more diagnostic and therapeutic decision making than ever before. Now in addition to clear educational needs in the ambulatory arena, general internists may require additional training (or, at least, not less training) in inpatient medicine, in chronic disease management across the spectrum of inpatient and outpatient care. General internists of the future will need to be trained with attention to the integrative tasks of population-based monitoring of process quality and outcomes. They will need to learn about leadership skills and working in a team of providers. As work hours of residents decline, as medical knowledge expands, as medical care becomes more complex, and as patients live longer with more chronic medical illness, our residencies will be hard pressed to train general internists competent in inpatient and outpatient settings, in urban and rural environments, who are competent at managing chronic illnesses and caring for older adults. In addition to the obvious need for outstanding inpatient and outpatient clinical medicine, we anticipate that programs will need to incorporate the following: 1) longitudinal training directed to a specific population chosen by the resident (e.g., HIV, geriatrics, women's health, refugees), including population-based quality measurement and improvement techniques, and often across the spectrum of inpatient, outpatient, subacute, and home care; 2) opportunities for training in rural or community-based settings; 3) training in geriatrics to include subacute, chronic, and home care; 4) enhanced training in communication skills (including electronic) and in building and leading teams; 5) quality monitoring and quality improvement techniques; 6) enhanced opportunities for interested residents to gain skills in performing procedures, including skin biopsy, endometrial biopsy, casting, fine-needle aspiration, screening and other endoscopy, and basic cardiology procedures; and 7) education about information technology and medical informatics.

This task force believes that the current training system is inadequate for the needs of the present and future general internist. It is beyond the scope of this task force to make specific recommendations about the curricula, content, and length of residency training, but we are skeptical that so much can be taught in our current 3-year programs. ${ }^{53,54}$

Although internal medicine training has common and uniform characteristics across various programs, the same is not true for individual practices. Diversity of practice sites, patient populations, geography, and health care systems demands different sets of skills. While all internists generally will share core values and build on common skill sets, many recently trained internists are unprepared for their practice environment. Training programs that adapt to career goals should produce internists with better 
Table 1. Core Values of General Internal Medicine

\begin{tabular}{|c|c|}
\hline Core Values & $\begin{array}{c}\text { Core Value Attributes and } \\
\text { Competencies }\end{array}$ \\
\hline \multicolumn{2}{|l|}{$\begin{array}{c}\text { Expertise in adult } \\
\text { patient care* }\end{array}$} \\
\hline $\begin{array}{l}\text { Acquiring and } \\
\text { sharing } \\
\text { knowledge }\end{array}$ & $\begin{array}{l}\text { Providing patient-centered, } \\
\text { comprehensive, longitudinal care } \\
\text { Treating complex and chronic illnesses } \\
\text { Coordinating care in health systems } \\
\text { Commitment to quality outcomes } \\
\text { Commitment to preventive care } \\
\text { Expertise in geriatric medicine } \\
\text { Evidence-based practice of disease } \\
\text { prevention and health promotion } \\
\text { Using outstanding communication } \\
\text { skills } \\
\text { Establishing personal, ongoing doctor- } \\
\text { patient relationships } \\
\text { Cultural sensitivity and competency } \\
\text { Breadth and depth of knowledge } \\
\text { Practice of evidence (science)-based } \\
\text { medicine } \\
\text { Intellectual rigor } \\
\text { Information management } \\
\text { Education } \\
\text { Commitment to lifelong learning } \\
\text { Educating patients, other } \\
\text { professionals, and trainees } \\
\text { Adaptability } \\
\text { New knowledge } \\
\text { New diseases, treatments, } \\
\text { technology, information technology, } \\
\text { cultural diversity, and } \\
\text { communications }\end{array}$ \\
\hline Leadership & $\begin{array}{l}\text { Understanding context } \\
\text { Commitment to quality, quality } \\
\text { improvement, public good }\end{array}$ \\
\hline Professionalism & $\begin{array}{l}\text { Altruism } \\
\text { Accountability } \\
\text { Accessibility } \\
\text { Commitment to excellence } \\
\text { Duty and service } \\
\text { Honor and integrity } \\
\text { Respect for others } \\
\text { Equity }\end{array}$ \\
\hline
\end{tabular}

* Italics indicate core values and competencies that particularly distinguish general internal medicine.

preparation and skills for their work, raising the likelihood of meeting the needs of their patients and achieving greater career satisfaction. The interested reader can view 3 scenarios, illustrating tailor-made mastery training for rural medicine and for hospitalist medicine in private practice and academic settings, at http://www.sgim.org/futureofGIM.pdf.

Internal medicine training programs need radical restructuring to accomplish what we have set forth. We recommend that SGIM, with other academic and practice organizations, convene a group of educators to review current data on our residency programs' successes and failures and to set concrete guidelines for the ideal training program for the future general internist. The group should establish a common base of breadth, depth, and mastery for all general internists at each point in their trainingand determine what general internists will not be expected to know or master. Instead of simply adding expectations for everyone in the field, training must be tailored to the various contexts in which general internists will practice.

Any new model of training should incorporate expected levels of competence at graduation in each of the areas necessary for future practice as a general internist. A few extraordinary residents might take 2 or 3 years to attain these levels and graduate, while others might take 4 years or even longer. ${ }^{53,54}$ We hope that as part of this process, the convened group will work with the Accreditation Council for Graduate Medical Education (ACGME) and American Board of Internal Medicine (ABIM) to create tracks within training programs for interested residents to qualify for certificates of added qualification (CAQs) as evidence of their training. We hope that reinvigorated training will "raise the bar" of general internal medicine ${ }^{53}$ as mastery will enhance professional satisfaction and the attractiveness of the field.

Increased opportunities and flexibility to lengthen the residency should let generalists in internal medicine develop along different generalist tracks, including hospital- and office-based and rural practitioners, geriatrics, medicine-pediatrics, and other general areas of in-depth mastery in internal medicine.

Previous proposals to restructure training programs have been in vain, because large academic medical centers receive significant financial rewards for inpatient, academic rotations, and limiting training in ambulatory, communitybased, and rural sites off-campus. We predict some of the most profound objections to our current proposal will come from academic hospitals and departments-where turf may be threatened, especially if community-based teaching changes the flow of graduate medical education funding. Medicare training dollars currently flow to hospitals, not to educational directors or even directly to departments. Replacing residents on inpatient wards with other providers or with attending-only services is necessary to liberate time, but expensive to implement. ${ }^{37,54}$ Also, our current concept of the "best" teachers does not usually include busy nonacademic practitioners as potentially some of the most desirable mentors and trainees-yet many practicing physicians are well-suited to teach the skills that the generalist of the future will need.

The restructuring of training hinges not only on redistributing graduate medical education funding, but also on fee restructuring to reward physicians for the team leadership, electronic communication, disease management, and comprehensive-usually longitudinal-coordinated care that future generalists will practice. To attract students to our field, which is vital to our nation's future health, will likely require reimbursement reform. Internists will need a payment system with incentives (as opposed to today's fee-for-service disincentives) to provide telephone and electronic communications, avoid unnecessary procedures, and provide population-based supervision. ${ }^{25,38}$ 
Although many students enter medical school with career aspirations for primary care, the educational process often derails those goals. This has led to a serious, progressive decline in the number of medical school graduates choosing primary care specialties, including internal medicine. Without attention to the issues of career choice for these potential future internists, all of the recommendations in this report are rhetorical.

\section{Research}

Over the past quarter century, academic generalists have made important contributions to clinical research, addressing a wide array of issues, especially those relevant to routine practice. ${ }^{10}$ Their work has emphasized seeing whether medical interventions, such as tests or therapies, truly benefit typical patients under usual clinical circumstances. Public investment in medical research has grown dramatically during the past decade, as the National Institute of Health's current $\$ 27.5$ billion budget shows. ${ }^{55}$ However, relatively little support is for research on effectiveness and everyday clinical care. ${ }^{56}$ Thus, as today's conscientious clinicians try to apply existing technology efficiently and effectively, the pipeline of new developments promises hope for vastly improved patient well-being, while posing a potentially overwhelming challenge.

A serious reconsideration of national research priorities is needed. Concern has been growing that the massive investment in molecular biology and now gene therapy research has not yet yielded the substantial benefits expected in improved health for the American public. ${ }^{56-59}$ People alive today, particularly those with multiple chronic illnesses, need studies that help physicians apply existing technologies to achieve the greatest benefit, while conserving precious health care resources. Depending on the problems studied, various methods are appropriate, including traditional randomized trials, as well as nonrandomized, quasi-experimental, and descriptive studies. Even a relatively modest increase in support for such studies stands to furnish enormous public benefit.

However, the research agenda should also follow general internal medicine's paradigm shift, testing the new care models we propose and aiming to improve the practice of our field and of medicine as a whole. Such studies should not only evaluate single tests or limited interventions, because improving chronic illness management usually involves multifaceted interventions with coordination, comprehensiveness, and continuity, an activated patient, and systems to support patients and providers. ${ }^{24,30,31,60,61}$ Recent studies have demonstrated impressive gains for patients with depression, diabetes, asthma, and heart failure by reorganizing care delivery to ensure better coordination, system support, and active patient involvement. ${ }^{24-31,62-67}$ Studies showing the advantages of inpatient care provided by hospitalists compared to traditional or usual hospital care helped to establish the legitimacy of this new field. ${ }^{52,68,69}$ Innovations aimed to improve other aspects of generalist care, especially involving patients with several other chronic conditions, should be studied. Such studies will require creativity in designing new, potentially effective modes of care for chronic illness and imaginative methods of evaluation.

Researchers should also devote themselves to determining the depth, breadth, and special mastery areas of general internal medicine. In what areas must all general internists be competent? What areas are important in which practice sites and settings? Are there areas of the field where in-depth skills and knowledge are no longer relevant to the patients for whom general internists care? We need systematic research-engaging academic leaders, practitioners, managers, and policy makers - to calibrate training programs to reflect the current and likely future practice of medicine.

It is also essential that research be conducted to assess the quality of care delivered. ${ }^{30,70,71}$ New methods are needed to measure and improve the quality of care using the information in increasingly available electronic medical records. ${ }^{25}$ We need to tell the public that these studies can be conducted without compromising privacy, and that this research is worthy of funding, with a goal of ever-improved standards of care.

\section{SUMMARY}

Medicine today is in a state of chaos for doctors, patients, and payers. We recommend that general internal medicine move from confusion to innovation that is based on our abiding goal to improve patient care. The domain of general internists will continue to be primary and principal care of adults. Skills that can distinguish general internists and improve patient well-being include enhancing patient self-efficacy and managing information transparently, increasingly in direct partnership with patients. General internists should aspire to be skilled and knowledgeable so they and their teams can provide most of their patients' general ongoing medical care, including for common chronic diseases.

This paradigm shift will require major changes, especially developing a new system for reimbursement, overhauling the basic internal medicine residency, and responding to opportunities that technologic changes provide.

\section{RECOMMENDATIONS}

1. General internal medicine should remain true to its core values and competencies, although market forces may tempt the field to abandon them while adapting to chaos. Our field's strengths are critical to serving our patients' needs, promoting their well-being, and providing compassionate care. 2. The domain of our field should stay both broad and deep -ranging from providing or supervising uncomplicated primary care to delivering continuous care to patients with multiple, complex, chronic diseases. As the principal provider for adults, general internists need skills in gynecology, 
dermatology, orthopedics, otolaryngology, psychiatry, and the internal medicine subspecialties.

3. General internal medicine should embrace changes in information systems, especially those promising to enhance partnership with patients, promote self-efficacy, increase efficiency of care, reduce costs, and improve outcomes. 4. Postgraduate and continuing medical education should develop mastery-a key element for both patient and professional satisfaction. Mastery of our field should include care delivery, practice management, information systems, and team leadership skills, as well as the traditional internal medicine knowledge and skill base.

5. General internists should usually work in teams and provide services through their own direct contact with patients, traditional telephone communication (directly or through staff), and more and more asynchronous communication using e-mail and other new communication technologies. Wherever they practice, general internists should lead and be responsible for the care their team members give, aiming to be able to provide most of the care their patients require. 6. Current financing of physician services, especially feefor-service, must be abandoned, reformed, or restructured to include reimbursement for services provided outside of traditional face-to-face visits. Physicians should be reimbursed for time spent supervising long-term care, managing teams, and providing services by phone and e-mail. Alternatively, physicians could be paid a patient management fee plus reimbursement for specific services or a salary with incentives for productivity, quality, and improved outcomes. We endorse the development of reimbursement based on quality and outcomes.

7. General internal medicine residency training should be reformed and reconstituted to provide both broad, in-depth medical knowledge and mastery of additional skills in informatics, management, and team leadership. General internal medicine residents should have options to tailor the final 1 to 2 years of their program to meet the special needs of their anticipated practice and career goals, often earning a certificate of added qualification (CAQ) or its equivalent in special generalist fields. Subspecialists would typically diverge from internal medicine residency after 2 or 3 years. For this recommendation to be viable, reimbursement reform is required.

8. General internal medicine educators and researchers should emerge as leaders, promoting the changes in the academic world that this new vision implies. They will need the support of other academic leaders, especially department chairmen. Skill development and research must expand to let faculty gain the mastery and tools to teach medical informatics, team leadership, and practice management. Research will expand to include practice and operations management, developing more effective shared decision making and transparent medical records, and promoting the close personal connection that both doctors and patients want. Research should continue not only to document but also to improve the value of generalist, comprehensive, and continuous care.

\section{REFERENCES}

1. Grumbach K. Primary care in the United States- the best of times, the worst of times. N Engl J Med. 1999;341:2008-10.

2. Moore G, Showstack J. Primary care medicine in crisis: toward reconstruction and renewal. Ann Intern Med. 2003;138:244-7.

3. Association of American Medical Colleges. Decline of medical school applicants continues in 2002: projections for 2003 indicate rebound 2002 Press Release http://www.aamc.org/newsroom/pressrel/ 2002/021030.htm. Accessed September 16, 2003.

4. Association of American Medical Colleges. Medical student graduation questionnaire: all schools summary. 2002 data report, http:// www.aamc.org/data/gq/allschoolsreports/2002.pdf. Accessed September 16, 2003.

5. Newton DA, Grayson MS. Trends in career choice by US medical school graduates. JAMA. 2003;290:1179-82.

6. Landon BE, Reschovsky J, Blumenthal D. Changes in career satisfaction among primary care and specialist physicians, 19972001. JAMA. 2003;289:442-9.

7. Shanafelt TD, Sloan JA, Habermann TM, Association of Professors of Medicine. The well-being of physicians. Am J Med. 2003;114:513-9.

8. Linzer M, Konrad TR, Douglas J, et al. Managed care, time pressure, and physician job satisfaction: results from the physician worklife study. J Gen Intern Med. 2000;15:441-50

9. Schroeder SA. Primary care at a crossroads. Acad Med. 2002;77:767-73.

10. Larson EB. General internal medicine at the crossroads of prosperity and despair: caring for patients with chronic diseases in an aging society. Ann Intern Med. 2001;134:997-1000.

11. Wong MD, Shapiro MF, Boscardin WJ, Ettner SL. Contributions of major diseases to disparities in mortality. N Engl J Med 2002;347:1585-92.

12. Committee on Quality of Health Care in America Institute of Medicine. Crossing the Quality Chasm: A New Health System for the 21st Century. Washington, DC: National Academies Press; 2001; also available at http://www.iom.edu/report.asp?id=5432.

13. Kohn LT, Corrigan JM, Donaldson MS, eds. Committee on Quality of Health Care in America, Institute of Medicine. To Err Is Human Building a Safer Health System. Washington, DC: National Academies Press; 1999; also available at http://www.iom.edu/ report. .asp?id $=5575$.

14. Sandy LG. Homeostasis without reserve-the risk of health system collapse. N Engl J Med. 2002;347:1971-5.

15. Anderson GF. Physician, public, and policymaker perspectives on chronic conditions. Arch Intern Med. 2003;163:437-42.

16. Peabody FW. The care of the patient. JAMA. 1927;88:877-82.

17. Haslam D. "Schools and hospitals" for "education and health" general practice, not hospital care, accounts for most of health service. BMJ. 2003;326:235-6.

18. Safran DG. Defining the future of primary care: what can we learn from patients? Ann Intern Med. 2003;138:248-55.

19. Zuger A. In an age of specialists one doctor is primary. New York Times. January 7, 2003.

20. Haas JS, Cook EF, Puopolo AL, et al. Is the professional satisfaction of general internists associated with patient satisfaction? J Gen Intern Med. 2000; 15:122-8.

21. Eysenbach G. Infodemiology: the epidemiology of (mis) information. Am J Med. 2002; 113:163-5.

22. Reiser SJ, Banner RS. The charter on medical professionalism and the limits of medical power. Ann Intern Med. 2003;138:844-6.

23. Heisler M, Bouknight RR, Hayward RA, Smith DM, Kerr EA. The relative importance of physician communication, participatory decision making, and patient understanding in diabetes selfmanagement. J Gen Intern Med. 2002;17:243-52

24. Wagner EH, Austin BT, Davis CL, et al. Improving chronic illness care: translating evidence into action. Health Aff (Millwood). 2001;20:64-78.

25. Showstack J, Lurie N, Larson EB, Rothman AA, Hassmiller S. Primary care: the next renaissance. Ann Intern Med. 2003;138:268-72. 
26. Casolino L, Gillies RR, Shortell SM, et al. External incentives, information technology, and organized processes to improve health care quality for patients with chronic diseases. JAMA. 2003;289:434-41.

27. Lesser CS, Ginsburg PB. Health care cost and access problems intensify: initial findings from HSC's recent site visits. Issue Brief: Findings from HSC. 2003;63:1-6.

28. Moore G, Showstack J. Primary care medicine in crisis: toward reconstruction and renewal. Ann Intern Med. 2003;138:244-7.

29. Reinertsen JL. Zen and the art of physician autonomy maintenance. Ann Intern Med. 2003;138:992-5.

30. Bodenheimer T, Wagner E, Grumbach K. Improving primary care for patients with chronic illness: the chronic care model. JAMA. 2002;288:1775-9.

31. Bodenheimer T, Wagner EH, Grumbach K. Improving primary care for patients with chronic illness: the chronic care model, part 2 JAMA. 2002;288:1909-14.

32. Ayanian JZ, Guadagnoli E, McNeil BJ, Cleary CD. Treatment and outcomes of acute myocardial infarction among patients of cardiologists and generalist physicians. Arch Intern Med. 1997; $157: 2570-6$

33. Weingarten SR, Lloyd L, Chiou CF, Braunstein GD. Do subspecialists working outside of their specialty provide less efficient and lower-quality care to hospitalized patients than do primary care physicians? Arch Intern Med. 2002;162:527-32.

34. Ayanian JZ, Landrum MB, Guadagnoli E, Gaccini P. Specialty of ambulatory care physicians and mortality among elderly patients after myocardial infarction. N Engl J Med. 2002;347:1678-85.

35. Sandy LG, Schroeder SA. Primary care in a new era: disillusion and dissolution? Ann Intern Med. 2003;138:262-7.

36. Leigh JP, Kravitz RL, Schembri M, Samuels SJ, Mobley S. Physician career satisfaction across specialties. Arch Intern Med. 2002; 162:1577-84

37. Schroeder SA, Showstack JA, Gerbert B. Residency training in internal medicine: time for a change? Ann Intern Med. 1986;104: 554-61.

38. Ginsberg PB. Payment and the future of primary care. Ann Intern Med. 2003;138:233-4.

39. McMurray JE, Linzer M, Konrad TR, et al. The work lives of women physicians: results from the Physician Work Life Study. The SGIM Career Satisfaction Study Group. J Gen Intern Med. 2000;15:372-80.

40. Frank E, McMurray JE, Linzer M, Elon L. Career satisfaction of US women physicians. Arch Intern Med. 1999;159:1417-26.

41. Dorsey ER, Jarjoura D, Rutecki GW. Influence of controllable lifestyle on recent trends in specialty choice by US medical students. JAMA. 2003;290:1173-8.

42. Hoffman C, Rice D. Chronic Care in America: A 21st Century Challenge. Princeton, NJ: The Robert Wood Johnson Foundation; 1996

43. Anderson G, Horvath J. Chronic Conditions: Making the Case for Ongoing Care. Baltimore, Md: Johns Hopkins University; 2002.

44. Mijka M. As Americans age, geriatricians go missing. JAMA. 2002;287:1792-3.

45. Fisher ES, Wennberg DE, Stukel TA, et al. The implications of regional variations in Medicare spending. Part 1: the content, quality, and accessibility of care. Ann Intern Med. 2003;138:273-87.

46. Fisher ES, Wennberg DE, Stukel TA, et al. The implications of regional variations in Medicare spending. Part 2: health outcomes and satisfaction with care. Ann Intern Med. 2003;138:288-98.

47. Phelps CE. What's enough, what's too much? Ann Intern Med. 2003:138:348-9.

48. Wilensky G. The implications of regional variations in Medicare: what does it mean for Medicare? Ann Intern Med. 2003;138:350-1.

49. Halvorsen G. Kaiser Permanente. Ann Intern Med. 2003;138:232.
50. Romano M. Fever and chills: physician pay survey again shows wide disparities. Modern Healthcare. July 21, 2003; 29-31.

51. Thurow LC. Building wealth. Atlantic Monthly. 1999;283:57-69.

52. Wachter RM, Goldman L. The hospitalist movement 5 years later. JAMA. 2002;287:487-94.

53. American College of Physicians Task Force on Physician Supply. The role of the general internist defined. Ann Intern Med. 1994;121: 616-22.

54. Davidoff F. Advanced internal medicine (AIM). The training program in primary care internal medicine at the University of Connecticut School of Medicine. Conn Med. 1981:45:167-74.

55. Lenfant C. Shattuck lecture-clinical research to clinical practicelost in translation? N Engl J Med. 2003;349:868-74.

56. Sung NS, Crowley WF, Genel M, et al. Central challenges facing the national clinical research enterprise. JAMA. 2003;289:1278-87.

57. Rosenberg RN. Translating biomedical research to the bedside: a national crisis and a call to action. JAMA. 2003;289:1305-6.

58. Hening S, Quon AS, Meyer R, Korn D. The Changing Landscape for Clinical Research. Washington, DC: Association of American Medical Colleges; 1999.

59. Ochs J. Providers, plans misinformed about vendor software capability. Manag Care. 2002;11:48-9.

60. Rothman AA, Wagner EH. Chronic illness management: what is the role of primary care? Ann Intern Med. 2003;138:256-61.

61. Horowitz CR, Goldberg HI, Wagner EH, et al. A randomized controlled trial of continuous quality improvement and academic detailing to implement clinical guidelines. J Qual Improv. 1996;22:734-50.

62. Goldberg HI, Wagner EH, Fihn SD, et al. A randomized controlled trial of academic detailing and continuous quality improvement techniques: increasing compliance with national guidelines for the primary care of hypertension and depression. Jt Comm J Qual Improv. 1998;24:130-42.

63. Katon W, Von Korff M, Lin E, et al. Collaborative management to achieve treatment guidelines. Impact on depression in primary care. JAMA. 1995;273:1026-31.

64. Katon W, Robinson P, Von Korff M, et al. A multifaceted intervention to improve treatment of depression in primary care. Arch Gen Psychiatry. 1996;53:924-32.

65. Katon W, Von Korff M, Lin E, et al. Stepped collaborative care for primary care patients with persistent symptoms of depression: a randomized trial. Arch Gen Psychiatry. 1999;56:1109-15.

66. Wells KB, Sherbourne C, Schoenbaum M, et al. Impact of disseminating quality improvement programs for depression in managed primary care: a randomized controlled trial. JAMA. 2000; 283:212-20.

67. Hedrick SC, Chaney EF, Felker F, et al. Effectiveness of collaborative care depression treatment in VA primary care. J Gen Intern Med. 2003;18:9-16.

68. Auerbach $\mathrm{AD}$, Wachter RM, Katz P, et al. Implementation of a voluntary hospitalist service at a community teaching hospital: improved clinical efficiency and patient outcomes. Ann Intern Med. 2002;137:859-65.

69. Melzer D, Manning WG, Morrison J, et al. Effects of physician experience on costs and outcomes on an academic general medicine service: results of a trial of hospitalists. Ann Intern Med. 2002;137:866-74.

70. Kitahata MM, Koepsell TD, Deyo RA, et al. Physicians' experience with the acquired immunodeficiency syndrome as a factor in patients' survival. N Engl J Med. 1996;334:701-6.

71. Indridason OS, Coffman CJ, Oddone EZ. Is specialty care associated with improved survival of patients with congestive heart failure? Am Heart J. 2003;145:300-9. 